\title{
Behavior of a strip footing on reinforced soil subjected to inclined load
}

\author{
Jawdat Abbas ${ }^{1, *}$ \\ ${ }^{1}$ Civil Engineering Department, University of Tikrit, Tikrit, Iraq
}

\begin{abstract}
This study investigates the behavior of a strip footing under inclined load on reinforced sandy soil by using experimental model. The effect of the load inclination angle $(\alpha)$, number of geogrid layers $(\mathrm{N})$ and the relative density $\left(\mathrm{R}_{\mathrm{D}}\right)$ on the bearing capacity, settlement and horizontal displacement were studied. The results showed that by increasing the number of reinforcement layers $(\mathrm{N})$, the bearing capacity increased, but there is an optimum value $(\mathrm{N}=4-5)$ depending on relative density of supporting soil. Also the settlement and horizontal displacement of footing decreasing with increase number of reinforcement layers.
\end{abstract}

\section{Introduction}

The load from structure is transformed to the supporting soil by foundations. Foundations usually are constructed with a larger area to minimize the pressure. Many types of footings are used for different applications. A strip footing which is largely used to support bearing walls is used in this research. The strip footing is rectangular in form but its length is much greater than its width. Strip footing can be analyses in two dimensions.(plane strain conditions). Footings of building are often under inclined loading such as footings under a vertical and horizontal loads, structure's nature or earthquake[1].

The load inclination leads to reduce the bearing capacity of the supporting soil by sliding the footing and heaving the supporting soil. This could be avoided either by building the footing with larger dimensions to minimize the contact pressure which causes uneconomical design or by raising the "bearing capacity" of the soil under footings.

Many researchers have written on the effective utilization of soil reinforcement as a economical way to enhance the bearing capacity of soil beneath foundations. This could be done by replacing the poor field soil up to a certain depth by the soil or fills of the same soil back with place as horizontal sheets of geosynthetics at different depths beneath the footings. So that, with the potential advantage of utilizing soil reinforcement both the type and the size of footing may be changed leading to an economic design[2,3,4,5,6,7,8,9].

There are many types of geosynthetics according to function and application, (geotextiles, geogrids, geonets, geomembranes, geopipes, geofoam, geocomposite, etc.). Geogrids are plastic made into very open, grid like configuration with large apertures between individual ribs in the machine and cross machine directions. The opening are usually $(12-100 \mathrm{~mm})$ in length and/or depth; geogrids are transported to the site in $(1-4 \mathrm{~m})$ width of rolls. Geogrids are formed in various ways[10].

The utilization of geogrid sheets could be particularly convenient when the mechanical properties of the soil under a foundation would suggest the designer in utilizing other solutions. Recently, the utilization of geogrids as a soil reinforcement has become prevalent, because geogrids are dimensionally stable and combine features such as high tensile modulus (low strain at high load), open grid structure which provides improved soil reinforcement interaction, positive shear connection properties, light weight, and more service life[11].

In this paper the bearing capacity, settlement and horizontal displacement of a strip footing subjected to inclined loading resetting on reinforced soil using experimental modeling was investigated.

\section{Laboratory model tests}

The testing devices consist of four parts, the test tank, model footing, the loading system, and vibratory system [12].

\subsection{Test box}

The test box used in this study made of steel plate with inside dimensions $900 \mathrm{~mm} \times 900 \mathrm{~mm}$ and $550 \mathrm{~mm}$ in height. The sides and the bottom were made of $6 \mathrm{~mm}$ thickness plate, the plate was supported by four steel channels, with $150 \mathrm{~mm}$ high from the base of the steel box. The internal surfaces of the box were oiled (in order to reduce the friction which may develop during the process). A mark lines were drawn to give the desired thickness of the layers and the position of reinforcement layer, plate (1) shows the test box[12].

* Corresponding author: dr.Jawdatkhadim@tu.edu.iq 


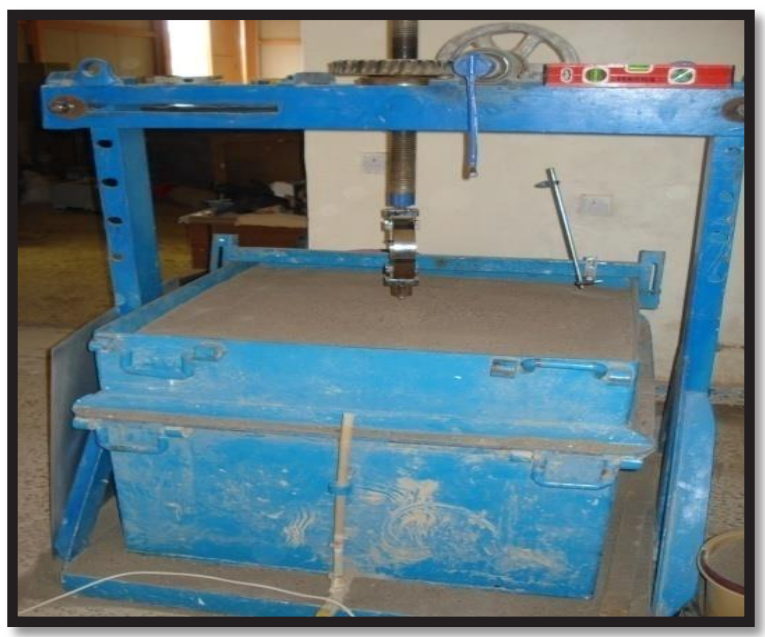

Plate (1): Test box

\subsection{Model of footing}

The test footing was a strip steel channel $80 \mathrm{~mm} \times$ $800 \mathrm{~mm}$. The load applied to the footing was counted using proving ring of $5 \mathrm{kN}$ capacity, while the vertical deflection and horizontal displacement of the footing was counted by three dial gauges $(0.01 \mathrm{~mm} /$ division $)$ as shown in Plate(2). The dimensions of footing model was selected depending on the size of the test box and the influence zone[12].

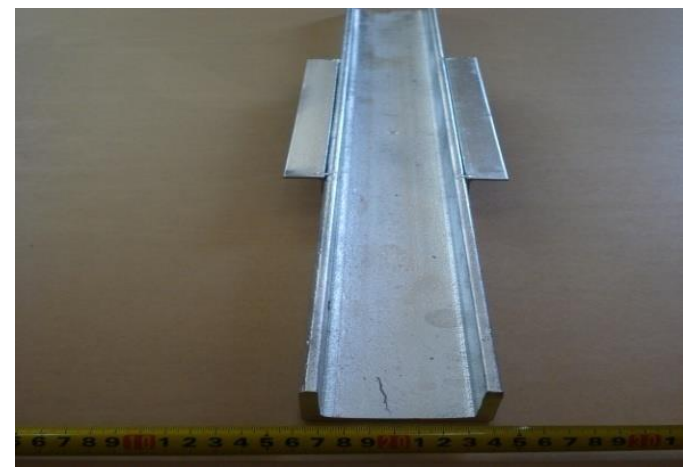

Plate (2:) Strip footings model

\subsection{The loading frame}

The test box was placed over $1100 \times 1100 \mathrm{~mm}$ strong steel base of $80 \mathrm{~mm}$ thick. The base was connected to a stiff loading frame, which was locally manufactured. As shown in Plate (3). The frame consists of two columns of steel channels $1520 \mathrm{~mm}$ height, which intern bolted to a loading platform. The platform was designed to slide along the columns and can be fixed at any desired height by means of slotted spindles and holes provided at different intervals along the two columns. The two steel columns were fixed by four short steel angle pieces connected to the lower plate in the frame[12].

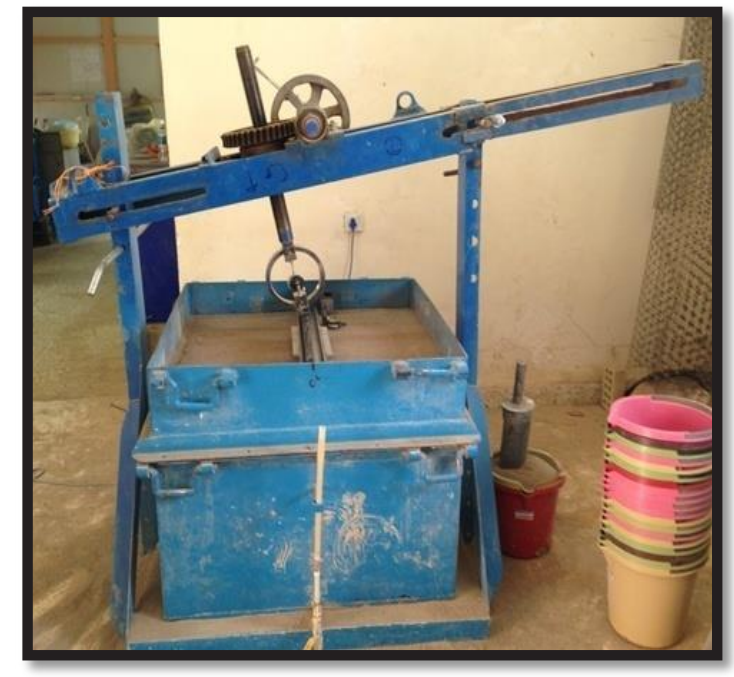

Plate (3): Loading system

\subsection{The loading system}

The load was applied by means of mechanical arrangement technique that was employed for the test. The proving ring was attached to a cylindrical steel toothed shaft device of $550 \mathrm{~mm}$ long and $40 \mathrm{~mm}$ diameter, which transfers the load to the footing and help to adjust the height of ring to any position required before or after test. A steel plate was made for each one of the footings, as shown in plate (4) which was attached at the end of the proving ring and work to transfer loading as equally distributed line load. Three dial gauges were attached to the footing and fixed to measure the footing vertical and horizontal displacement.

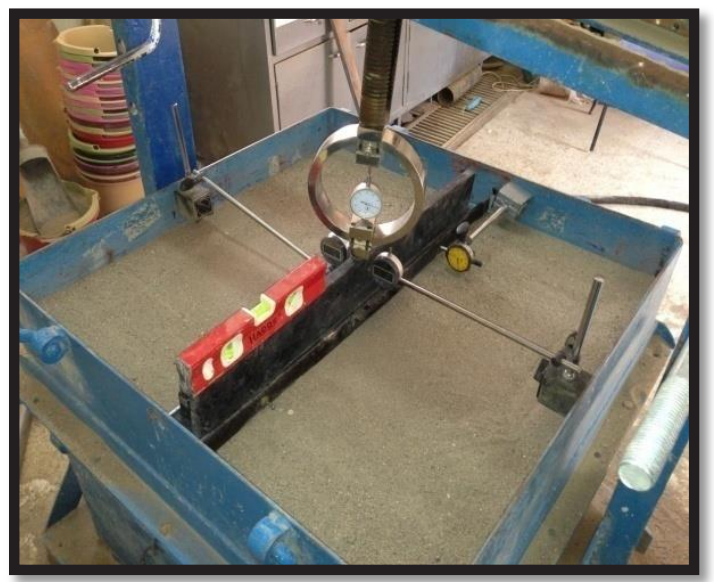

Plate (4): A steel plate model which transfer distributed line load on the strip footing.

\subsection{Vibration system}

To achieve the required relative densities, it is easier to use an electrical vibrator. This method based on placing 
the soil in the box in layers each layer of thickness $(50 \mathrm{~mm})$ then placing a plate $(700 \times 700 \mathrm{~mm})$ then moving the vibrator over the whole area of the plate in a specified time .The time needed to reach the required relative density was achieved by performing a series of trials with different measured time. In each trail, the densities were calculated by collecting samples in small aluminum cans of known volume put at different locations in the test tank[12].

\subsection{Experimental setup}

The footing was installed in position and the load was applied to it through the proving ring. The load was applied until failure happened. Vertical settlement and horizontal displacement of the footing for each load increment applied were recorded with the usage of dial gauges.

\section{Materials properties}

\subsection{Sand properties}

The soil used in this study, is sandy soil with the properties shown in Table(1). All the laboratory tests were conducted based on ASTM.[13]. The grain size distribution is shown in Figure (1).

Table 1. Soil properties used in this study.

\begin{tabular}{|c|c|c|}
\hline \multicolumn{2}{|c|}{ Properties } & Value \\
\hline \multicolumn{2}{|c|}{ Moisture content, $(\omega) \%$} & 1 \\
\hline \multicolumn{2}{|c|}{ Specific gravity, $\left(G_{s}\right)$} & 2.579 \\
\hline \multicolumn{2}{|c|}{ Coefficient of uniformity $\mathrm{Cu}$} & 3 \\
\hline \multicolumn{2}{|c|}{ Coefficient of curva ture $\mathrm{Cc}$} & 1 \\
\hline \multicolumn{2}{|c|}{ Unified Soil Classific ation System } & SP \\
\hline \multirow{2}{*}{ M.I.T classification } & Sand (\%) & 100 \\
\hline & Silt \& Clay (\%) & 0 \\
\hline \multicolumn{2}{|c|}{ Minimum dry unit weight, $\left(\mathrm{kN} / \mathrm{m}^{3}\right)$} & 14.873 \\
\hline \multicolumn{2}{|c|}{ Maximum dry unit weight, $\left(\mathrm{kN} / \mathrm{m}^{3}\right)$} & 17.975 \\
\hline \multicolumn{2}{|c|}{ For relative density $60 \%,\left(\mathrm{kN} / \mathrm{m}^{3}\right)$} & 16.594 \\
\hline \multicolumn{2}{|c|}{ For relative density $80 \%,\left(\mathrm{kN} / \mathrm{m}^{3}\right)$} & 17.255 \\
\hline
\end{tabular}

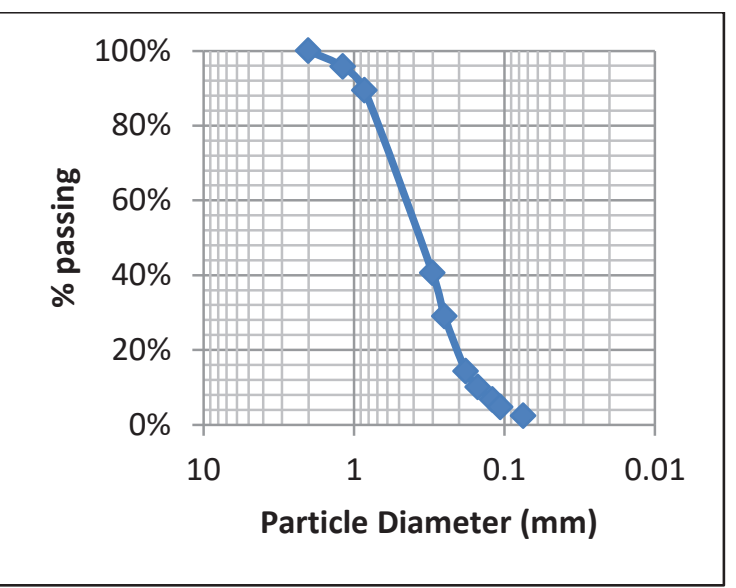

Fig.1. Particle Size Distribution of the sand

\subsection{Reinforcement layers}

The reinforcement material used in this study is Geogrid type "TriAx ${ }^{\circledR}$ TX140" Geogrid product from a punched polypropylene layer. The characteristics of a Geogrid sheet are shown in Table (2).

Table 2. Characteristics of Geogrid Reinforcement sheets used in this study

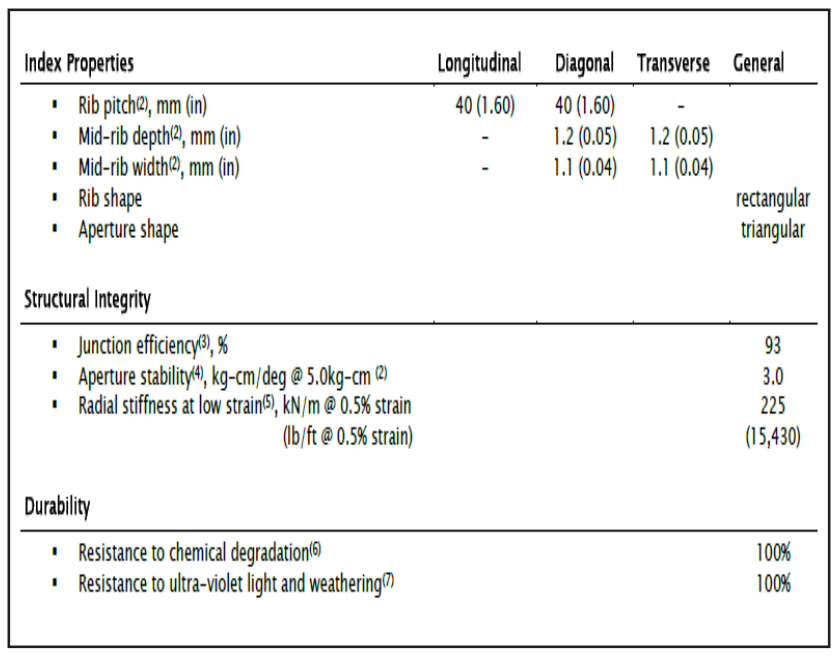

\section{Test program}

There are (48) tests conducted to reach the aim of the study. Eight tests were conducted on unreinforced soil. These tests are a reference to comparison and to know how much the improvement in the bearing capacity as a result of using the reinforcement by Geogrid. Also, they are used to determine the effect of variation in the angle of load inclination( $\alpha)$ on the bearing capacity of unreinforced soil for relative densities $(60 \% \& 80 \%)$. The remaining (40) tests which were representing the fundamental part of this research, show the effect of the multi-reinforcement layers on the bearing capacity, settlement and horizontal displacement. 


\section{Results and discussion}

There are several parameters, which affect the behavior of a strip footing subjected to inclined loading resting on reinforced sandy soil. In this study, most of these parameters were varied within their reasonable ranges in order to explore their effects on the bearing capacity and on each other. The effects of the following parameters : load inclination angle $(\alpha)\left(0^{\circ}, 5^{\circ}, 10^{\circ}\right.$, and $\left.15^{\circ}\right)$, number of geogrid layers (N) from (1 to 5 layer), and for two relative densities $(60 \%$ and $80 \%)$ to represent medium dense and dense sand are studied. The depth of first layer (U) is taken equal to $0.35 \mathrm{~B}$ while the vertical distance between reinforcement layers ( $h$ ) is taken equal to 0.25B.[12]

The expression bearing capacity ratio (BCR) is presented to calculate the effect of Geogrid reinforcement on the bearing capacity and it can be written as:

$$
\mathrm{BCR}=\frac{\mathrm{q}_{u r}}{\mathrm{q}_{\mathrm{u}}}
$$

Figure (2) show the major reinforcement parameters of strip footing subjected to inclined load on reinforced sandy soil.

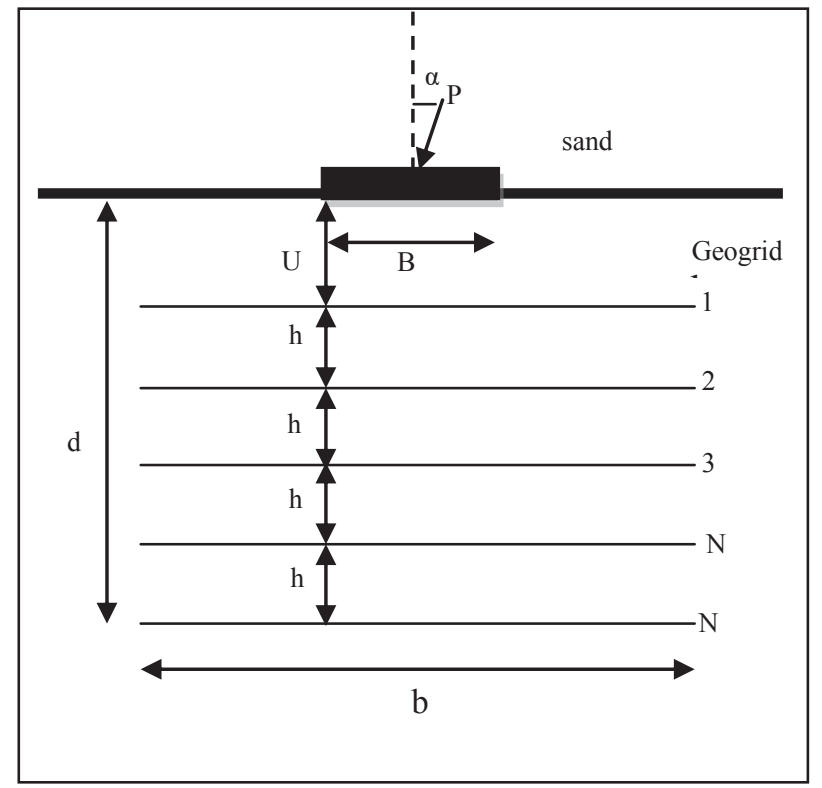

Fig. 2. Major reinforcement parameters of inclined loaded strip footing.

\subsection{Effect of load inclination ( $\alpha$ )}

In order to investigate the effect of the variation of load inclination angle $(\alpha)$ on the ultimate bearing capacity of strip footing, (8) tests have been conducted for several cases.

Figures (3) and (4) show the bearing pressuresettlement curves for different load inclination $(\alpha)$ for two relative densities on unreinforced sand. It is evident from the pressure-settlement curves, that as the inclination of the load is increased, the settlement due to failure pressure decreases. Besides the decrease in settlement, the values of the ultimate bearing capacity decreases with an increase in the load inclination too. This happened because of increasing the horizontal load component. The horizontal component of the load increases the lateral stress on the surrounding zone, leaving the less resistance to support the vertical stress generated by the load vertical component [Sowers and Sowers, 1951].

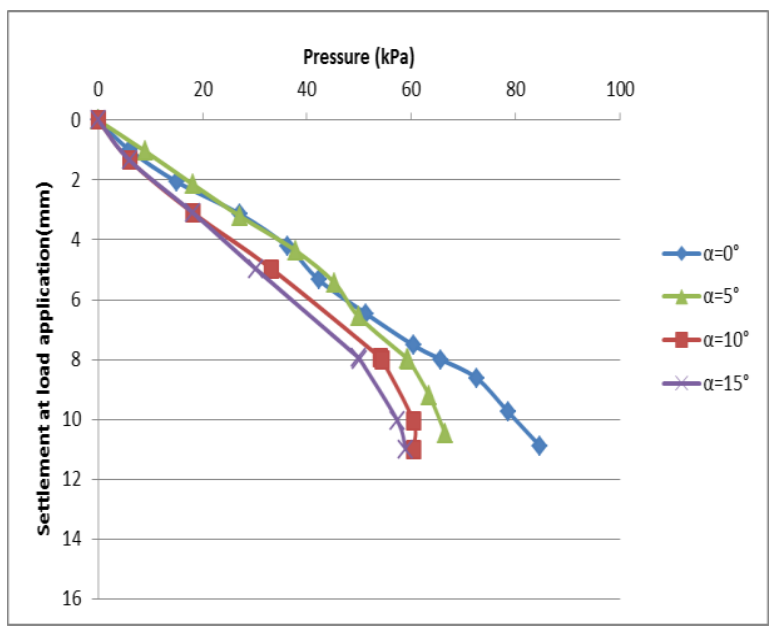

Fig. 3. Pressure-settlement curves for different $(\alpha), R_{D}=60 \%$, $\mathrm{N}=0$

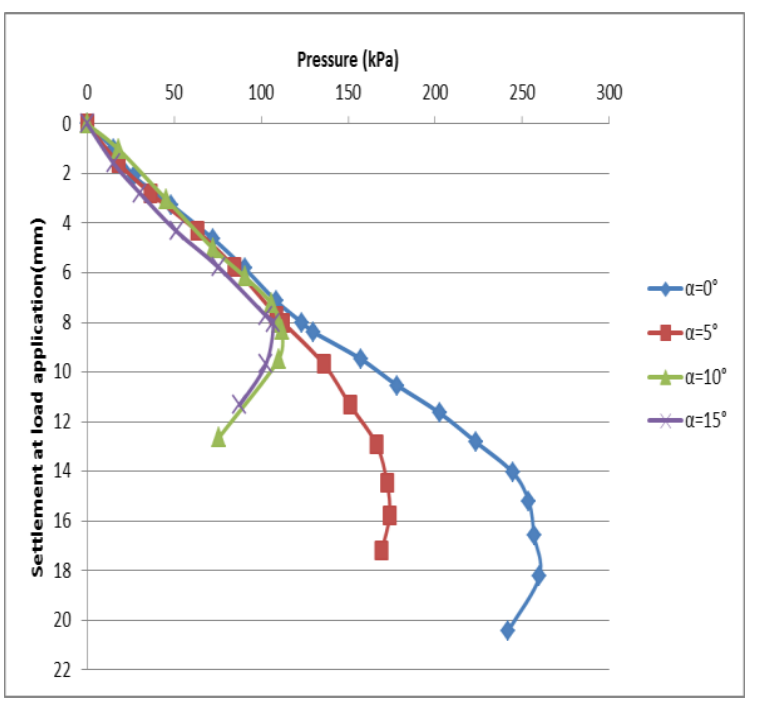

Fig. 4. Pressure-settlement curves for different $(\alpha), \mathbf{R}_{\mathbf{D}}=\mathbf{8 0} \%$, $\mathbf{N}=\mathbf{0}$.

Figures (5) and (6) show the bearing pressure-horizontal displacement curves for different load inclination $(\alpha)$ for two relative densities on unreinforced sand. By observing the curves of pressure-horizontal displacement of all cases, it can be concluded that the horizontal displacement is increased with an increasing of the load inclination $(\alpha)$. 


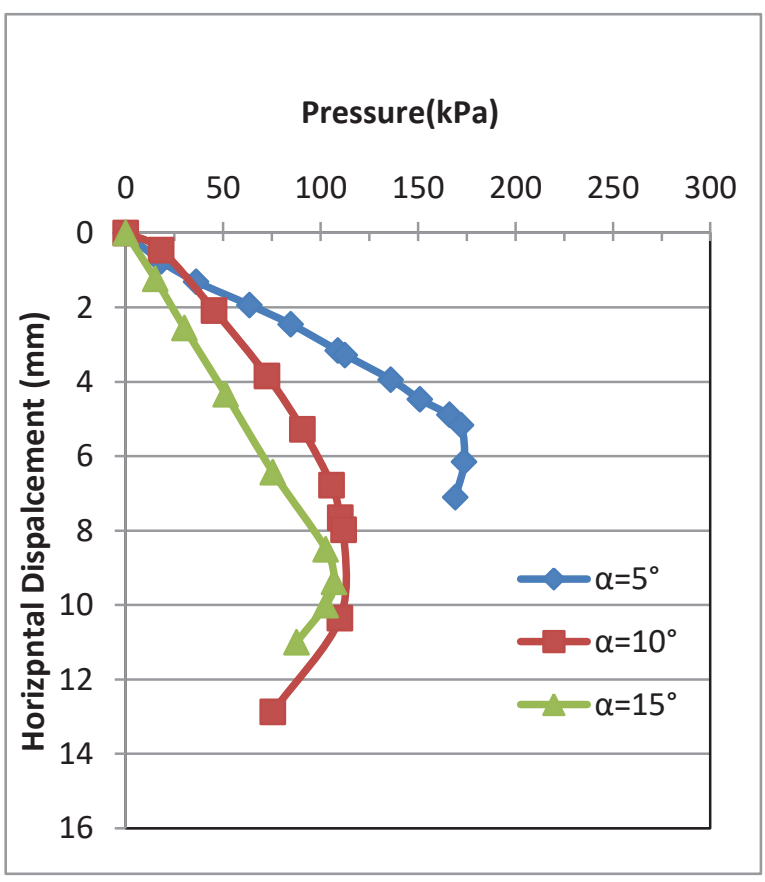

Fig. 5. Pressure-horizontal displacement curves for different $(\alpha) R_{D}=60 \%, N=0$

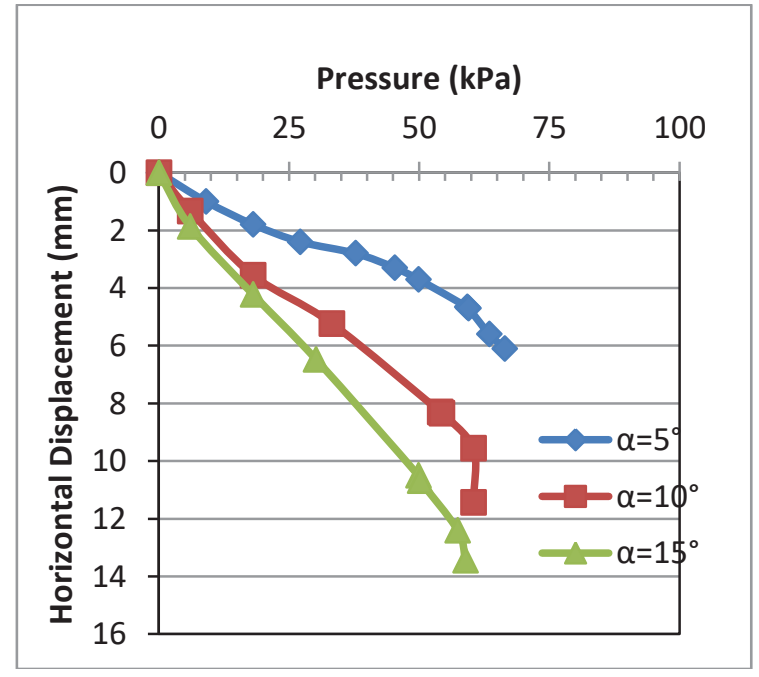

Fig. 6. Pressure-horizontal displacement curves for different $(\alpha) R_{D}=80 \%, N=0$

\subsection{Effect of Geogrid Layers}

In order to investigate the effect of the change the number of geogrid layers $(\mathrm{N})$ on the ultimate bearing capacity, (36) tests have been conducted for several cases. Figures (7) and (8) show the relationship between the number of geogrid layers $(\mathrm{N})$ and the bearing capacity ratio (BCR) for different values of load inclinations $(\alpha)$ for relative densities $60 \%$ and $80 \%$, respectively. It is noticed that the (BCR) significantly increased with the increase of the number of geogrid layers. In addition, it is noticed that there is an optimum value of $(\mathrm{N})$ after which little increase in the value of
(BCR) is observed. The reason of this behavior can be clarified as the number of geogrid increase the length of the shear failure surface increased. The second reason is that by increasing the numbers of geogrid layers, the tensile stress which can be carried by the geogrid will increased too. As the results of both reasons, the resistance of the soil against shear failure will increase too.

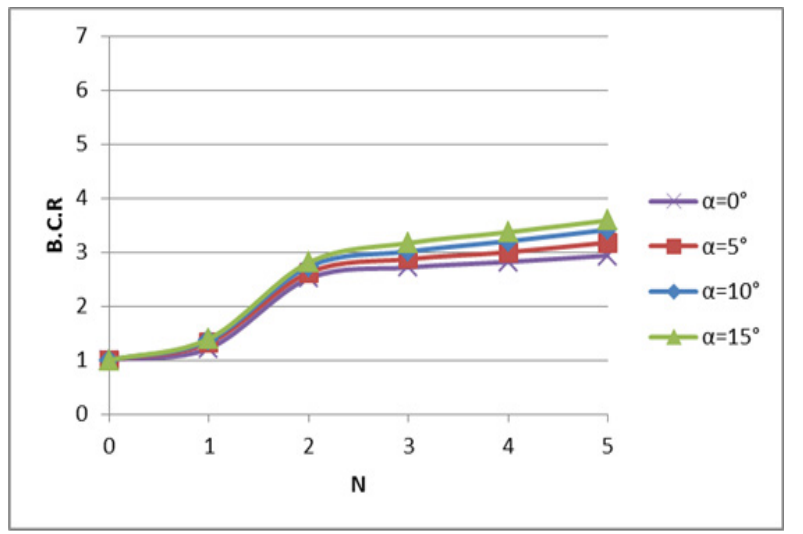

Fig. 7. Bearing capacity ratio (BCR) versus Number of reinforcement layer $(\mathrm{N})$ for $\left(\alpha=0^{\circ}, 5^{\circ}, 10^{\circ}\right.$ and $\left.15^{\circ}\right)$ and $(\mathrm{RD}=60 \%)$.

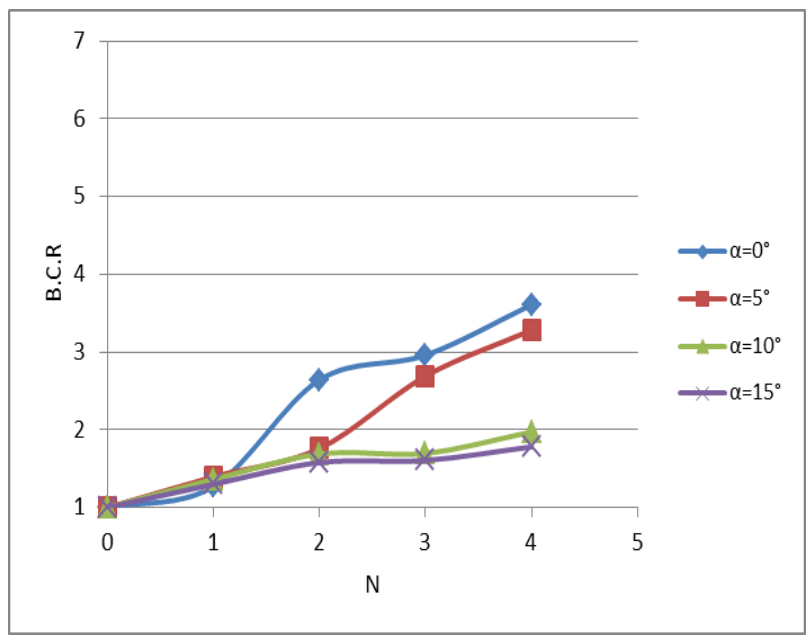

Fig. 8. Bearing capacity ratio (BCR) versus Number of reinforcement layer $(\mathrm{N})$ for $\left(\alpha=0^{\circ}, 5^{\circ}, 10^{\circ}\right.$ and $\left.15^{\circ}\right)$ and $(\mathrm{RD}=80 \%)$.

Figure (9) and (10) show the effect of number of reinforcement sheets $(\mathrm{N})$ on the horizontal displacement of the footing which is due to load inclinations $(\alpha)$. It can be seen that the increasing of the reinforcement $(\mathrm{N})$ decreases the horizontal displacements for different values of load inclination $(\alpha)$ for relative densities $60 \%$ and $80 \%$, respectively. 


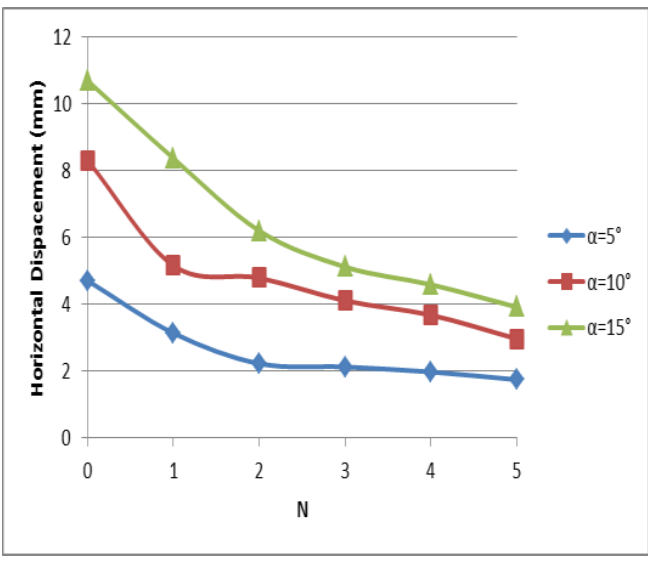

Fig. 9. Horizontal displacement (mm) versus Number of reinforcement layer $(\mathrm{N})$ for different values of $(\alpha)(\mathrm{RD}=60 \%)$.

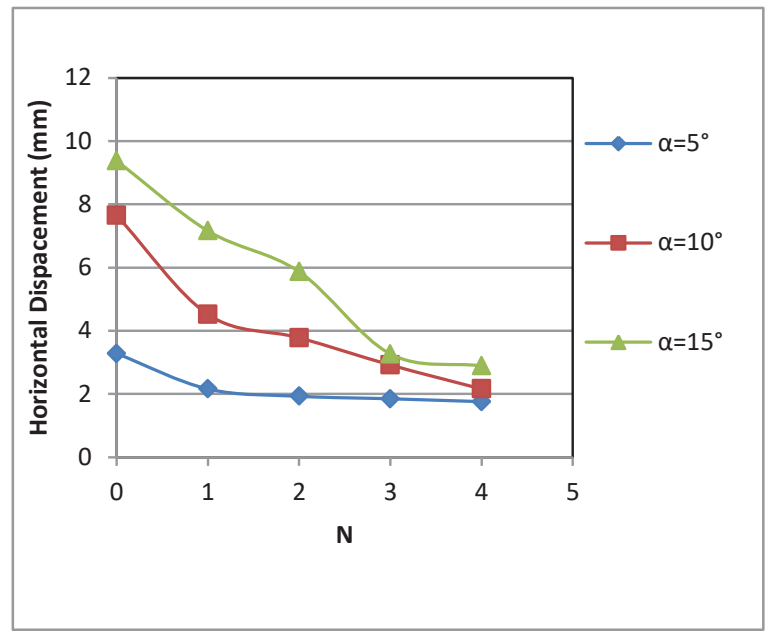

Fig. 10. Horizontal displacement (mm) versus Number of reinforcement layer $(\mathrm{N})$ for different values of $(\alpha)$ and $(\mathrm{RD}=$ $80 \%)$.

Figures (7) to (10) show the influence of the relative density $\left(R_{D}\right)$ on the bearing capacity ratio $(B C R)$ and on horizontal displacements for different values of load inclination $(\alpha)$ for relative densities $60 \%$ and $80 \%$, respectively. It can be seen that the increase of the relative density $\left(R_{D}\right)$ decreases the $(B C R)$ and decreasing the optimum number of reinforcement $(\mathrm{N})$ and reduce the horizontal displacement of the footing which is due to load inclination $(\alpha)$. This could be explained because the soil has been improved and it was observed for the two chosen values of $\left(R_{D}\right)$. In addition, it is noticed that the (BCR) for the medium dense sand is larger than that for dense sand. This means that the reinforcement is more sufficient for medium dense sand than for dense sand considering the unreinforced loaded case for each of them as a reference, according to the definition of (BCR).

It should be mentioned that Figures (7) to (10) could be used by practicing engineers as design charts to obtain the number of reinforcement layers required to cancel or to reduce the effect of load inclination or even to increase the factor of safety. Table (3) show the magnitude of enhancement in the bearing capacity of strip footing when use geogrid reinforcement layer for different values of load inclination angle and for two relative densities. $(60 \%$ and $80 \%)$.

Table 3. Effect of Geogrid Multi-reinforcement layers on Bearing Capacity Ratio

\begin{tabular}{|c|c|c|c|c|c|c|c|c|}
\hline $\begin{array}{c}\mathrm{R}_{\mathrm{D}} \\
\%\end{array}$ & $\alpha$ & \multirow{2}{*}{$\mathrm{q}_{\mathrm{u}}$} & \multicolumn{6}{|c|}{$\mathrm{N}$} \\
\cline { 3 - 9 } & & & 0 & 1 & 2 & 3 & 4 & 5 \\
\hline \multirow{5}{*}{60} & $0^{\circ}$ & 65. & 1.0 & 1.4 & 2.5 & 2.7 & 2.8 & 2.9 \\
& & 7 & 0 & 97 & 12 & 15 & 17 & 34 \\
\cline { 2 - 9 } & $5^{\circ}$ & 59. & 1.0 & 1.5 & 2.6 & 2.9 & 2.9 & 3.1 \\
\cline { 2 - 9 } & & 5 & 0 & 75 & 21 & 69 & 97 & 7 \\
\hline & 10 & 54. & 1.0 & 1.6 & 2.7 & 3.0 & 3.2 & 3.4 \\
& $\circ$ & 4 & 0 & 80 & 33 & 11 & 01 & 13 \\
\cline { 2 - 9 } & 15 & 50. & 1.0 & 1.7 & 2.8 & 3.1 & 3.3 & 3.5 \\
& $\circ$ & 2 & 0 & 58 & 10 & 67 & 67 & 85 \\
\hline \multirow{5}{*}{80} & $0^{\circ}$ & 123 & 1.0 & 1.2 & 2.6 & 2.9 & 3.6 & \\
& & .3 & 0 & 73 & 42 & 59 & 07 & \\
\cline { 2 - 9 } & $5^{\circ}$ & 112 & 1.0 & 1.3 & 1.7 & 2.6 & 3.2 & \\
\cline { 2 - 9 } & & .5 & 0 & 94 & 59 & 90 & 81 & \\
\cline { 2 - 9 } & $\circ$ & 112 & 1.0 & 1.3 & 1.6 & 1.6 & 1.9 & \\
\cline { 2 - 9 } & 15 & 106 & 1.0 & 1.2 & 1.5 & 1.6 & 1.7 & \\
& $\circ$ & .9 & 0 & 98 & 77 & 05 & 80 & \\
\hline
\end{tabular}

\section{Conclusions}

From the experimental results and their discussion stated in the above sections, the major conclusions are outlined below:

1. The results showed that using geogrid as a reinforcement material has a significant increased on the ultimate bearing capacity .

2. Bearing capacity increase with increasing in the number of reinforcement layers $(\mathrm{N})$, but there is an optimum value after which little effect is observed. This optimum value is varied $(\mathrm{N}=4-5)$ for relative densities $(80 \%$ and $60 \%)$, respectively.

3. Increasing the number of reinforcement layers $(\mathrm{N})$ lead to decreasing the horizontal displacement of the footing.

\section{References}

1. A. Amen, M.Sc. Thesis, Tikrit University, Iraq. (2008)

2. M. El Sawwaf, J. Geotechnical. and Geological Eng., Vol. 135, No. 10, pp. 1509-1518, (2009).

3. M. Omar, J. Pure and Applied Sciences, University of Sharjah, Vol. 3, No.2, pp. 35-51,( 2006).

4. C. Patra, R. Behera, N. Sivakugan, and B. Das, Int. f- Geotechnical. Eng., 6(2): 342-352, (2012).

5. R. Purkayastha, and R. Char, j. Geotechnical. Eng. Div., 103(6), 647-651.(1977).

6. S. Saran, S. Kumar, and A. Kumar, J. Geotechnical and Geological Eng, 25, 123137,(2007). 
7. E. Shin, and B. Das, Geosynthetics Int., Vol. 7, No. 1, pp. 59-71.( 2000).

8. E. Shin, B. Das, E. Lee, and C. Atalar, J. geotechnical and geological engineering, 20(2), pp.169-180,(2002).

9. Al-Taay, M.Sc. Thesis, Tikrit University, Iraq, (2010).

10. R. Koerner, Designing with Geosynthetics, 5th Edition, Pearson Prentice Hall, USA, (2005).

11. C. Patra, B. Das, M. Bhoi, and E. Shin, J. Geotextiles and Geomembranes, 24(4), 254-259, (2006).

12. M. Al-Zandi, M.Sc. Thesis, Tikrit University, Iraq , (2013).

13. ASTM, Vol. 04.13 Geosynthetics, West Conshohocken, United State ,(2004). 